\title{
WEAR RATES IN URBAN RAIL SYSTEMS
}

\author{
RICCARDO LICCIARDELLO, GABRIELE MALAVASI, STEFANO RICCI \& PIETRO VITALI \\ Sapienza Università di Roma, DICEA Dipartimento di Ingegneria Civile e Ambientale, Italy
}

\begin{abstract}
A significant part of maintenance costs in urban rail systems (metro, tram, light rapid transit/light metro) is due to wheel-rail wear. Wear rates; measured for example as depth of wear per kilometre run (rolling stock) or per train passage (rails) depend in a complex manner on several influence factors. Among the most important are key design factors of the rolling stock (wheel profiles, suspension characteristics), of the track (distribution of curve radii, characteristics of switches and crossings, rail profiles), of the wheel-rail interface (lubrication, materials in contact, ambient characteristics), and of operations (frequency of traction and braking, trainset inversion policy, maintenance policy etc.). When designing an urban rail system, all of these factors have to be under control in order to limit the costs due to wheel/rail reprofiling/grinding and replacement. The state of the art allows the calculation of wear rates given quantitative input regarding the above factors. However, it is difficult to find in the literature experimental values for calibration of wear models and indications on what is a reasonable state of the art wear rate for any given type of urban rail system. In this paper we present a structured analysis of flange wear rates found in the literature and derived from the experience of the authors, for a variety of cases, including metros and mainline rail systems. We compare the wear rates and explain their relationship with the influence factors. We then relate the wear rates with the needs in terms of wheel reprofiling/replacement. We estimate ranges for the calibration coefficients of wear models. We present the results in a way as to allow the designer of urban rail systems to derive values for target wear rates according to their specific conditions without the need for complex simulations.

Keywords: urban railway, wheels, rails, wear, metro, tram.
\end{abstract}

\section{INTRODUCTION}

Urban rail systems constitute in general a safe, green and quick way to move around town. However, they are costly systems to maintain, and although their societal benefits are high, the utmost care has to be taken to keep costs as low as possible considering moreover that they are funded ultimately with taxpayers' money. Therefore, it is extremely important for the scientific community to address any aspect that can lead to cost reduction whilst maintaining or improving the other qualities of the system.

One of these aspects is one of the "fundamentals" of wheel-rail systems: wear of wheels and rails. In spite of decades of research and application, this is still attracting the interest of researchers and designers alike. For the latter, in particular, what is useful is to be able to make quick estimates of wear rates as a basis for:

- the choice of wear mitigation systems;

- wheel and rail maintenance plans;

- the definition of contractual aspects (component lifetime and maintenance requirements).

For such aspects, the complex approaches generally found in the literature, addressing the prediction of the evolution of wheel and rail profiles over time, can be excessively demanding in terms of time and cost required. Moreover, it is extremely difficult to find the necessary data to feed the mathematical models.

The aim of this paper is to point towards a research direction that focuses more on key aspects for rail system design: 
- $\quad$ simple approaches;

- quantities actually relevant for maintenance, addressed normatively and informing decision-making criteria (reprofiling, grinding, etc.), such as flange thickness and wheel diameter;

- $\quad$ orders of magnitude/values of expected wear rates under specific conditions, with more contributions from full-scale field experiments.

Fig. 1 shows the dimensions of interest for the wheel. In this paper, we focus on flange thickness $e$, which for urban contexts is often the control variable for decisions on flange wear maintenance (reprofiling). Correspondingly the wear rate of interest regards flange thickness reduction per unit distance run, measured here in micrometres $/ \mathrm{km}$ $(\mu \mathrm{m} / \mathrm{km})$.

The process that determines the lifetime of the wheel is a superposition of running wear and removal of wheel material due to reprofiling. On lines with few curves (this is seldom the case in urban contexts), the wheel tread wears down relatively quickly with respect to the flange, and so the diameter wear rate dominates (often reprofiling occurs due e.g. to an excessive diameter difference between the two wheels of the same axle). In the more usual case for urban contexts, wheels come into the workshop for reprofiling due to the flange thickness reaching some lower limit: in Fig. 2 the wheel profile has reached its lower limit (e.g. $27.5 \mathrm{~mm}$ ) because of the wheel repeatedly flanging in curves, and reprofiling has restored the nominal value of $32.5 \mathrm{~mm}$. It is clear from Fig. 2 that this cannot be done without reducing the wheel diameter by a certain amount, depending on the shape acquired by the worn profile (variable from wheel to wheel). For example, in Fig. 2 it has been necessary to remove $20 \mathrm{~mm}$ from the diameter to restore the $5 \mathrm{~mm}$ required by the flange.

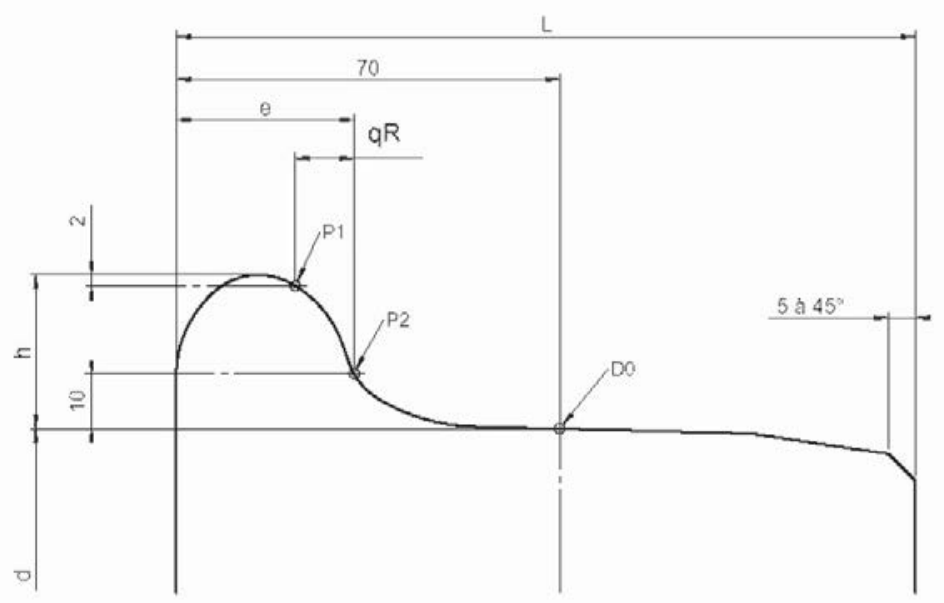

Figure 1: Dimensions of interest regarding the transversal wheel profile; in this paper we are interested essentially in flange thickness $e$ and wheel diameter DO. (Source: EN 15313:2010 [1].) 


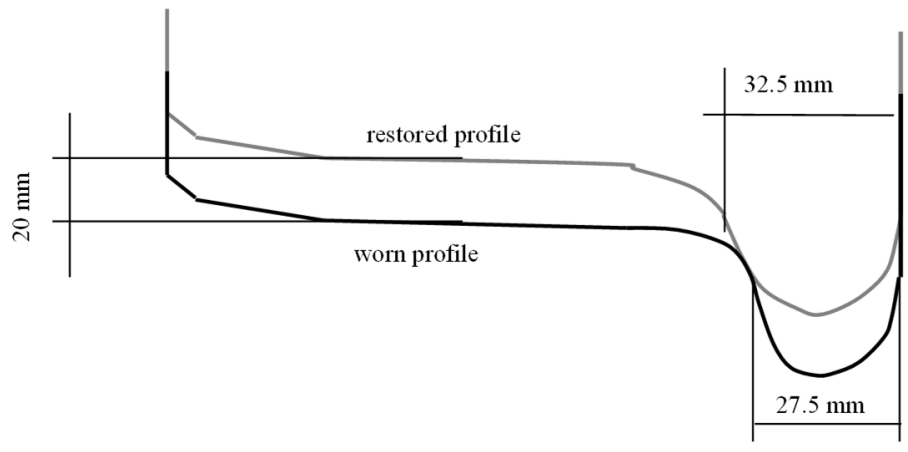

Figure 2: Indicative illustration of wheel reprofiling to restore flange thickness.

It is thus clear that the wheel's lifetime depends on wear in a rather complex way: the diameter decreases both to wear and to reprofiling events, the latter occur when the flange thickness reaches a lower limit and the amount of material removed depends on the shape of the worn profile.

Therefore, the simplest possible wheel profile lifetime model includes:

- $\quad$ assuming a quantity for which reprofiling will occur (in this case flange thickness);

- estimating the rate of wear associated to that quantity;

- estimating the modification of the profile due to reprofiling;

- iterating until the lifetime limit is reached (in this case the wheel diameter).

The first step is thus to look at the flange wear rates.

\section{ANALYSIS OF FLANGE WEAR RATES}

\subsection{Wear rate values}

The literature was analysed to identify cases in which wheel flange (thickness) wear rates are reported, particularly for urban rail systems. The data from this investigation regarding wear rates and corresponding service conditions are fairly rare (see [2]-[5]). The cases in Table 1 were identified as relevant to initiate the work. They refer to railway type wheel profiles (i.e. for Vignole type rails and not grooved rails as in many tram systems), and are thus more suited for reasoning with metro systems/light rapid transit.

It can be seen that the flange thickness wear rate is generally of the order of magnitude of $0.100 \mu \mathrm{m} / \mathrm{km}$, corresponding to $10,000 \mathrm{~km}$ run per millimetre worn, or 50,000 km run per 5 millimetres worn (i.e. when reprofiling is required according to usual practice).

Values as low as $0.021 \mu \mathrm{m} / \mathrm{km}$ (almost $250,000 \mathrm{~km}$ between reprofiling) and as high as $1 \mu \mathrm{m} / \mathrm{km}(5,000 \mathrm{~km}$ between reprofiling) are reported. The wear rate is reported to depend on the phase of the life of the wheel (initial phases, later phases), and opposite behaviours are observed - i.e. sometimes increase (Fig. 3), sometimes decrease (Fig. 4) of wear rate with distance run ("mileage"). The only paper that goes into detail on the very initial stages of wheel life [5] shows a very high initial wear rate. 
Table 1: Flange thickness wear rates for a number of cases.

\begin{tabular}{|c|c|c|c|c|}
\hline $\begin{array}{l}\text { Case } \\
\text { study }\end{array}$ & $\begin{array}{l}\text { Rolling } \\
\text { stock } \\
\text { type }\end{array}$ & Curve radii & Reference & $\begin{array}{l}\text { Flange thickness wear } \\
\text { rates }\end{array}$ \\
\hline A & metro & $\begin{array}{l}\text { min. } 248 \mathrm{~m} \\
\text { (1 tight curve, } \\
\text { the remainder } \\
\text { being high } \\
\text { radius) }\end{array}$ & [2] & $\begin{array}{l}0.030 \mu \mathrm{m} / \mathrm{km} \text { in the first } \\
80,000 \mu \mathrm{km} \text {, increasing } \\
\text { up to } 0.140 \mu \mathrm{m} / \mathrm{km} \text { at } \\
195,000 \mathrm{~km}\end{array}$ \\
\hline B & $\begin{array}{l}\text { driving } \\
\text { trailer } \\
\text { coach } \\
\text { for } \\
\text { suburba } \\
\mathrm{n} \text { rail }\end{array}$ & $262-800 \mathrm{~m}$ & [3] & $\begin{array}{l}0.060 \mu \mathrm{m} / \mathrm{km} \\
\text { in the first } 50,000 \mathrm{~km} \text {, } \\
\text { subsequently decreasing }\end{array}$ \\
\hline $\mathrm{C}$ & $\begin{array}{l}\text { high } \\
\text { speed }\end{array}$ & not known & [4] & $\begin{array}{l}0.028-0.047 \mu \mathrm{m} / \mathrm{km} \text { in } \\
\text { the first } 60,000 \mathrm{~km} \\
0.021-0.036 \mu \mathrm{m} / \mathrm{km} \text { in } \\
\text { the first } 120,000 \mathrm{~km} \text {, } \\
\text { subsequently decreasing }\end{array}$ \\
\hline D & $\begin{array}{l}\text { train for } \\
\text { regional } \\
\text { services }\end{array}$ & not known & [5] & $\begin{array}{l}1 \mu \mathrm{m} / \mathrm{km} \text { in the first } \\
2,500 \mathrm{~km}\end{array}$ \\
\hline $\mathrm{E}$ & $\begin{array}{l}\text { light } \\
\text { rapid } \\
\text { transit }\end{array}$ & $\begin{array}{l}50 \% \text { with radii } \\
\text { between } 100 \text { e } \\
300 \mathrm{~m}\end{array}$ & $\begin{array}{l}\text { calculation } \\
\text { for } \\
\text { this paper }\end{array}$ & $\begin{array}{l}0.056-0.100 \mu \mathrm{m} / \mathrm{km} \\
\text { in the first } 100,000 \mathrm{~km} \\
\text { (forecast) }\end{array}$ \\
\hline
\end{tabular}

The last case listed is a theoretical case calculated by the authors with Multi-Body Simulations (MBS) to determine wheel-rail contact forces (see e.g. Bruner and Rizzetto [6]) and frictional power, and a wear model calibrated on the basis of available experimental data (wheel profile measurements at different distances run on a number of trainsets, under "fair" contact conditions - e.g. lubrication, contamination). The calculation was undertaken in order to control the input conditions and influence factors and understand what figures would be obtained for the flange wear rates.

The mathematical modelling is illustrated in $\S 3$. The following data were assumed:

- $\quad$ bogie wheelbase: $1.8 \mathrm{~m}$.

- $50 \%$ of curves with radius between $100 \mathrm{~m}$ and $300 \mathrm{~m}$ (with significant flange contact).

- 24 daily runs.

- 2 daily runs to/from the depot, with depot curve radii of $102 \mathrm{~m}$ and $35 \mathrm{~m}$.

- trainset inversion policy such as to have $50 \%$ of runs with one trainset orientation with respect to the line and $50 \%$ with the opposite orientation - i.e. uniform wear of wheels on either side of the trainset.

- "fair" contact surface conditions (sufficiently lubricated and little contamination).

It is clear that the wear rates depend on service conditions. For instance, it is not surprising that the lowest wear rates are observed for the high-speed case, in which flange contact is expected to occur less frequently than for urban applications. 


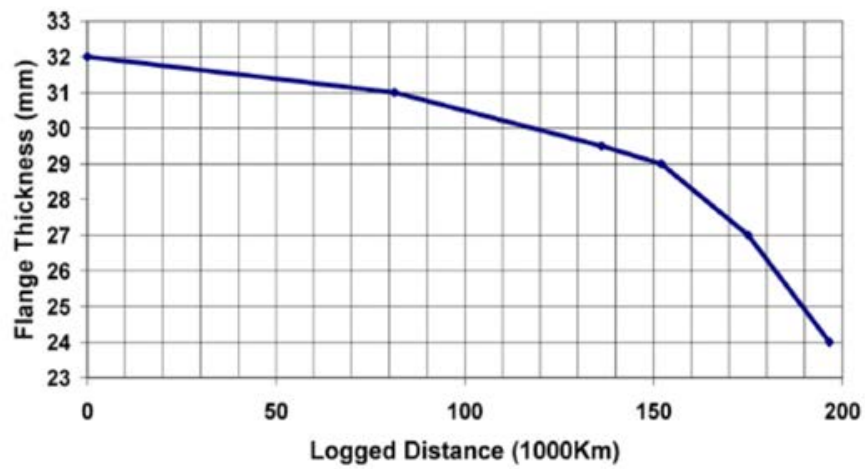

(a)

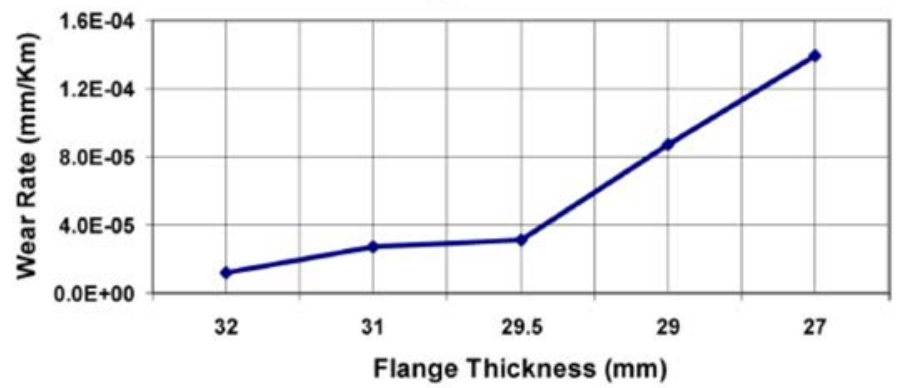

(b)

Figure 3: Flange thickness and wear rate for case A. (Source: Ansari et al., 2008 [2].)

(a)

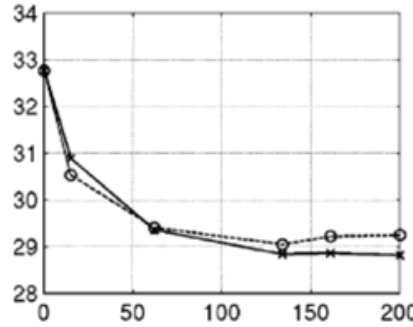

(c)

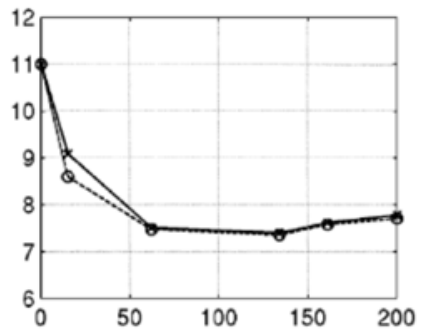

(b)

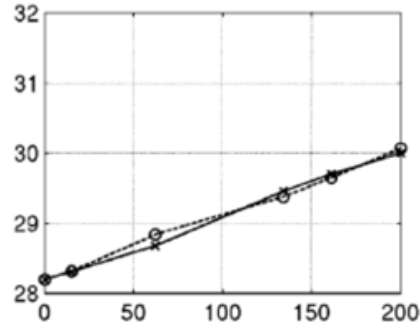

(d)

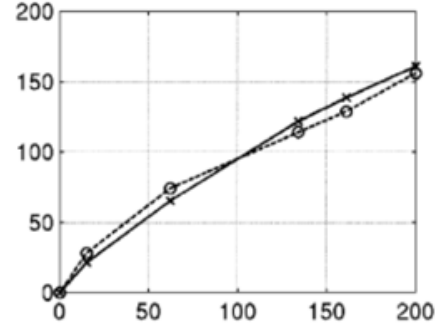

Figure 4: Flange thickness (diagram (a)) and other characteristic dimensions for case B (Source: Jendel, 2002 [3].) 
For the urban rail cases, Table 1 would suggest that obtaining a wear rate of less than $0.050 \mu \mathrm{m} / \mathrm{km}(100,000 \mathrm{~km}$ between reprofiling) could be considered as a good achievement. However, as mentioned, this depends on service conditions - should the line under consideration be perfectly straight for example, a target value of practically zero should be obtained.

\subsection{Wear rate influence factors}

Many aspects of vehicle/track design and operations influence the wear of wheel flanges. In fact, wear occurs due to the wheels running through curves in flanging conditions, i.e. most often when the wheel is performing its guiding function as outer wheel of the leading wheelset (of a bogie if it is a bogie vehicle). Flanging of the inner wheel of the trailing wheelset may occur on very tight curves - this is an undesirable condition that sometimes cannot be avoided, so its occurrence is kept to a minimum. Flanging also occurs when running through turnouts - particularly when actually turning out of a main line but possibly for very short distances also when running straight through. Flange contact may also occur on straight track due to hunting instability, but this is a highly undesirable condition which should be rarely encountered.

From this point of view, the main track-related influence factors are the number and length of curves and their radius (including depots, sidings etc.). Curve cant (and consequent cant deficiency or corresponding unbalanced lateral acceleration) also play a (lesser) role. Moreover, in metro systems track layout is such as to have close-to-zero unbalanced lateral acceleration for comfort and safety of standing passengers. Traction and braking, as well as rolling radius difference in curves, have an effect mostly on tread wear.

Regarding vehicle design, it is well known that (bogie) wheelbase depends on curve radius, with short wheelbases being necessary for tight curves. A low wheelbase/radius ratio generally leads to lower guiding forces, having fixed the remaining influencing factors and generally lower flange wear. Suspension design is also important, as designs offering for example the flexibility necessary for the wheelsets to be aligned radially with respect to the curve lead to lower guiding forces and generally lower wear.

Most importantly, it is the wheel-rail contact conditions that influence wear rates. Suitable compatible nominal wheel-rail profiles and materials can be important contributions to the achievement of low wear rates, taking into account that grooved rails may undergo flange-back and corresponding rail surface wear on tram lines.

Above all, an extremely important contribution generally comes from adequate lubrication of the flange, rail gauge-corner or both with the aim of reducing the friction force $T$ generated by the guiding force, also eventually in combination with lubrication of the top of the rail with so-called friction modifiers which act on the entity of the guiding force itself. The choice of on-board and/or wayside devices depends essentially on the track layout: where curves are few, then wayside devices, capable of lubricating up to a few kilometres of rail, may be convenient. Otherwise on-board devices are required.

Finally, in addition to the above design aspects there are relevant operational and maintenance aspects, among which:

- $\quad$ wheel profile maintenance (reprofiling installations, tools, staff expertise);

- lubrication system maintenance;

- $\quad$ rail grinding measures;

- trainset inversion policy. 


\section{WEAR MODELS AND CALIBRATION COEFFICIENTS}

There is a vast amount of literature on wear modelling. However, as we have seen in $\S 2$, there are not many wear rate values referred to specific conditions, nor many values used in wear models in order to match experimental wear rates measured in the field.

This information is quite valuable in the early stages of the design of an urban rail system, when one has to evaluate whether certain targets (for instance those indicated in a call for tenders) can be met, included in a draft maintenance plan for wheels and rails, and make some fundamental choices affecting the influence factors mentioned in $\$ 2.2$ (e.g. wheel-rail profile pair, wheelbase, lubrication system etc.).

The approaches indicated in the literature for this purpose have evolved over time, and now generally require Multi-Body Simulation used to feed wear models.

Wear models have not changed much over the years, and remain quite simple in terms of formulation. However more and more experimental data, particularly regarding lab tests (e.g. pin-on-disc, disc-on-disc) have become available. A possibility that can also be considered is the use of values of lateral forces derived from wayside force measurement systems installed on curves of different radius (see e.g. Cortis et al. [7]) or from on-board measurements (see e.g. Alessandria et al. [8]). There are a variety of models available for application to flange-rail contact, however the basic inputs are similar for all of them: essentially the guiding force and the degree of "sliding" of the wheel with respect to the rail, as measured through slip, creepage or equivalent quantities, are present in all models. The area $\left(\mathrm{mm}^{2}\right)$ of the contact zone is also included in some models, as well as for example the hardness of the softer contact material. The influence factors are combined so as to form socalled "Wear Numbers", to which the wear rate (measured in different ways - material loss, area loss, wear depth etc. according to the author) is considered proportional. Moving from one form of wear rate to another usually requires simple calculations (e.g. of the volume of wear from material loss and density and then derivation of the worn area considering the length of wear).

Here we refer to one of these wear models, namely the one developed by British Rail Research in the ' 80 s, described by Pearce and Sherratt [9] and widely cited and used, also in the literature given in the reference section of this paper. As input to this model, from the guiding force acting on the wheel of diameter $D$ (expressed in $\mathrm{mm}$ ), one must derive the total tangential force $T$ (i.e. the component due to friction) acting at the contact area and the corresponding relative creepage $\gamma$ due to the rolling-sliding contact. Once these values are known, the model identifies three different conditions and correspondingly three different formulae for the calculation of the wear rate $a$ measured in $\mathrm{mm}^{2}$ per kilometre run by the wheel under the same conditions, depending on the model's simple Wear Number, $T \gamma$

- if $\mathrm{T} \gamma<100 \mathrm{~N} \mathrm{~m} / \mathrm{m}$ (moderate wear) then

$$
\mathrm{a}=\mathrm{k} \cdot 0,25 \cdot \frac{\mathrm{T} \gamma}{\mathrm{D}}
$$

- if $100 \leq \mathrm{T} \gamma \leq 200 \mathrm{~N} \mathrm{~m} / \mathrm{m}$ (transition zone) then

$$
\mathrm{a}=\mathrm{k} \cdot \frac{25}{\mathrm{D}}
$$

- $\quad$ if $200<\mathrm{T} \gamma \mathrm{N} \mathrm{m} / \mathrm{m}$ (severe wear) then

$$
\mathrm{a}=\mathrm{k} \cdot \frac{(1,19 \cdot \mathrm{T} \gamma-154)}{\mathrm{D}} \text {. }
$$


A multiplying coefficient $k$ is introduced here with the purpose of matching available field experiment results and is assumed for simplicity to be the same in all three conditions. This approach is an attempt to overcome the fact that the above equations are theoretically valid for the pair of materials tested by British Rail only, incorporating possible behaviours due to different materials and surface conditions. For a wheel with $k=0.4$ and $D=710 \mathrm{~mm}$ (e.g. light metro case 5 of Table 1), the flange thickness reduction calculated from the area loss $a$ with simple geometrical considerations assuming a value for the height $h$ of the contact zone of $5 \mathrm{~mm}$ and a flange angle of $70^{\circ}$, we obtain the results of Fig. 5.

What is interesting to observe is that the wear rate is constant for a wide range of wear numbers (this behaviour is represented also in other wear models): e.g. a $T \gamma=200$, beyond which the wear rate increases dramatically, corresponds to $T=20 \mathrm{kN}$ and $\gamma=0.01$, or $T=2 \mathrm{kN}$ and $\gamma=0.1$. The key to maintaining it below 200 is keeping both $T$ low (limiting the guiding force and lubricating the flange contact) and $\gamma$ low (adequate contact geometry). These conditions are not easily achieved if the effects of the influence factors are not considered carefully and corresponding design and maintenance measures implemented. They are however achievable if the required care is used, for most curves on metro lines (possibly not in depots where curves are often of very low radius).

This consideration can sometimes simplify calculations in the early stages of design. In fact, the Multi-Body Simulations (MBS) typically used to calculate guiding forces and creepages could even be entirely avoided if one is confident in keeping the Wear Number below 200 and the calculations could be performed by simply assuming a (cautious) constant value for the Wear Number independently of curve radius.

\section{WHEEL/RAIL MAINTENANCE NEEDS}

Having introduced the problem, some initial reference values and the modelling approach generally used, in this section we look again at flange thickness wear rates from two different perspectives in order to evaluate their effects on maintenance needs and the conditions required to achieve them:

1. need to achieve a given wheel lifetime (i.e. mileage);

2. calculation with the model described in $\S 3$.

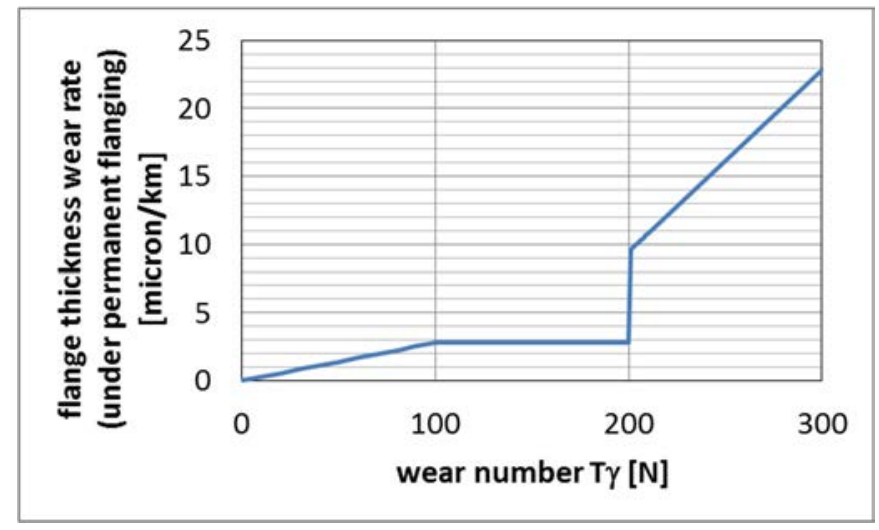

Figure 5: Flange thickness wear rate as calculated with the British Rail wear model, wheel diameter $\mathrm{D}=710 \mathrm{~mm}, \mathrm{k}=0.4$, contact area "height" $\mathrm{h}=5 \mathrm{~mm}$, flange angle $70^{\circ}$. 
For the first perspective, we refer to the example in Fig. 6. The evolution of flange thickness with mileage is represented for a hypothetical wheel, assuming three different constant wear rates: $0.025,0.050,0.100 \mu \mathrm{m} / \mathrm{km}$. The diameter wear is just visible but negligible if compared with the reduction due to reprofiling. This assumption is realistic for lines with many curves, in which the flange wears down comparatively quickly. With these assumptions three reprofiling operations are needed, as shown. Note that for only slightly higher values (e.g. $650 \mathrm{~mm}$ ) of minimum wheel diameter, the last reprofiling operation would lead to a wheel that would have to be removed from service and replaced, with a significant effect on its lifetime.

The chart clearly shows the relationship between wear rate and lifetime. It is particularly evident how lifetime depends on the reprofiling process quantified by the portion of diameter removed every time. In turn, this also depends somewhat on the shape the profile has assumed due to wear, and this justifies the abundant work done on estimating the evolution of profile shape, which has given rise to methods that however are not readily applicable in the early stages of design. Therefore, the wear rate on its own is not so important - it is rather the number of possible reprofiling operations that has the most significant influence on lifetime. Even a small reduction of the diameter removed each time can contribute in benefiting from a significant extension of lifetime when the wheel remains within the diameter limits. Considering that the wheel profiles assume a variety of not easily controlled shapes, this factor can be controlled essentially through the effectiveness of reprofiling operations only: machines used and staff expertise.

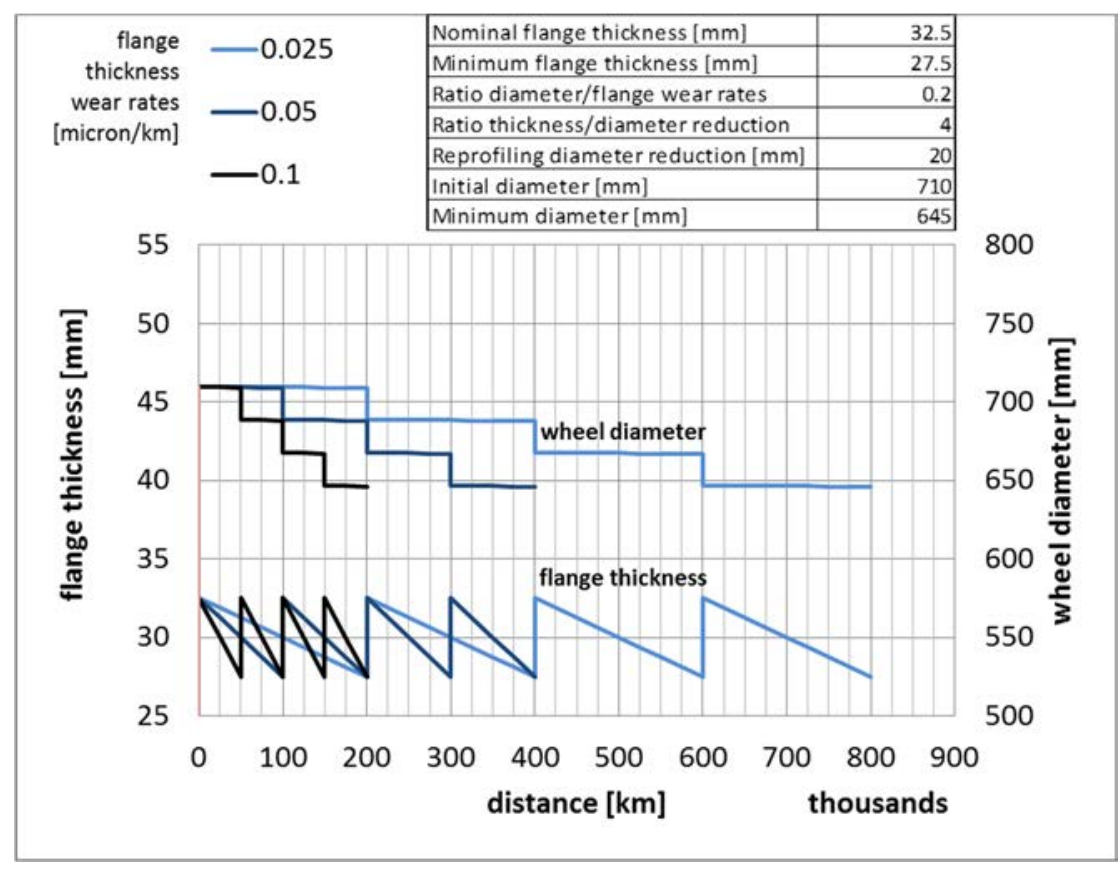

Figure 6: Evolution of flange thickness and wheel diameter during the life-time of three hypothetical wheels with three different (constant) flange wear rates. 
From the second perspective, we can broadly understand from Fig. 7 what is required to achieve the wear rates of Fig. 6. It refers to a hypothetical metro line with 10 sections each $1 \mathrm{~km}$ long, and each of which contains 1 curve (alternately left/right) of a given radius $R$ and length $L=100 \mathrm{~m}$ (line total length $L t o t=10 \mathrm{~km}$, total length of curves $L c=1,000 \mathrm{~m}$, $L c / L t o t=10 \%$ ). The trainsets run over this curve at a speed compatible with zero unbalanced lateral acceleration (zero cant deficiency). The design is such as to maintain the Wear Number below 200 (transition wear regime) on all curves up to the tightest, with no trainset inversion needed thanks to the symmetry of the line. Referring to Fig. 5, in which between Wear Number 100 and 200 the wear rate is approx. $2.8 \mu \mathrm{m} / \mathrm{km}$ (of curve), we can see that it is well translated into Fig. 7, which indicates $0.140 \mu \mathrm{m} / \mathrm{km}$ (of line) in this region, which is $1 / 2$ (alternating curves) $\times 0.1(10 \%$ of the total length $) \times 2.8 \mu \mathrm{m} / \mathrm{km}$.

If we wished to obtain an estimated wear rate for a line with $20 \% \mathrm{Lc} / \mathrm{Ltot}$ we would simply have to double the values of Fig. 7 and so forth for other LC / Ltot ratios.

From this chart, we can get a rough idea of the achievable wear rates given a ratio Lc / Ltot and a mean curve radius. The method is far from "exact", however it could be useful in the early stages of design. A $0.050 \mu \mathrm{m} / \mathrm{km}$ wear rate could be achieved with curve radius of $500 \mathrm{~m}$ if conditions of contact surfaces are "ordinary" or "fair". In order to obtain the same wear rate for lower curve radii (e.g. under $200 \mathrm{~m}$ ), the contact conditions should correspond to a coefficient $k$ of 0.2 , which definitely would require some care.

Depots can have an important effect on wear rates due to the presence of tight curves. Considering the case study of Fig. 7, if there are curves under 100 m radius, the conditions would enter the "severe" wear regime of Fig. 5. Similar calculations with a higher Wear Number (273 corresponding to $35 \mathrm{~m}$ curve radius) - show that with a curve-radius of $120 \mathrm{~m}$ and each trainset running over the depot curve once every 10 line-runs, the overall wear rate

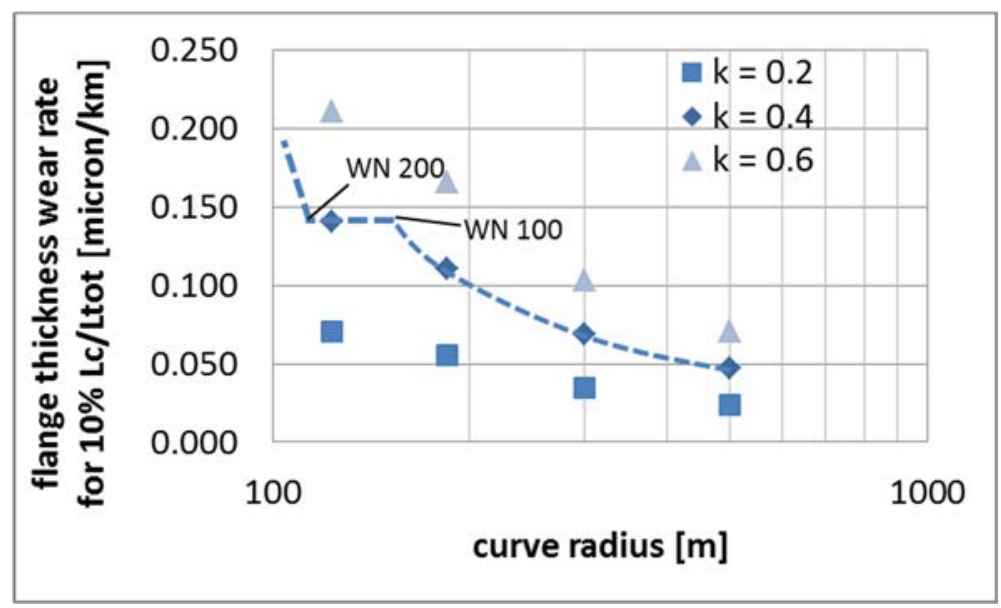

Figure 7: Flange thickness wear rate calculated with the British Rail wear model; Wear Number (WN) calculated by means of Multi-Body Simulation as a function of curve radius (zero unbalanced lateral acceleration); three different values of calibration coefficient $\mathrm{k}$; line of length Ltot made up of curves that are all the same radius and length (total length over the whole line Lc), alternately left and right; indicative trend is shown (related to Fig. 5). 
rises from 0.141 to $0.236 \mu \mathrm{m} / \mathrm{km}$. It is easy to imagine cases in which the line has a relatively high average radius (e.g. $300 \mathrm{~m})$ and sharp curves $(<100 \mathrm{~m}$ radius) only in the depot. In this case the overall wear rate would be dominated by the depot curves and by the number of times the trainsets enter the depot.

\section{CONCLUSIONS}

Flange wear in urban rail systems has always been and is still an important area for research. An important aim of such research is to facilitate the design and maintenance of such systems in order to obtain low wear rates, and thus lower the costs of these highly beneficial transport systems. When making design choices, time and budget are normally limited, therefore quick assessments of possible wear rates are necessary. This is not so easy based on the existing literature, which is focused on relatively complex approaches with few descriptions of full-scale experimental campaigns.

The intention of this paper was to set the basis for future research whose output will populate the literature with the missing information. To this end we examined the literature to identify published wear rates, we performed some simple modelling activities to confirm and justify the identified wear rates, we related the wear rates in a simplified approach to the maintenance needs for wheels, and provided some rough indications on what to expect in terms of wear rate according to the conditions.

[1] EN 15313:2010, Railway Applications. In-service wheelset operation requirements, In-service and off-vehicle wheelset maintenance.

[2] Ansari, M., Hazrati, I.A., Esmailzadeh, E. \& Azadi, S., Wear rate estimation of train wheels using dynamic simulations and field measurements. Vehicle System Dynamics, 46(8), pp. 739-759, http://dx.doi.org/10.1080/00423110701586436. 2008.

[3] Jendel, T., Prediction of wheel profile wear - comparisons with field measurements. Wear, 253, pp. 89-99, https://doi.org/10.1016/S0043-1648(02)00087-X. 2002.

[4] Enblom, R., Deterioration mechanisms in the wheel-rail interface with focus on wear prediction: A literature review. Vehicle System Dynamics, 47(6), pp. 661-700, http://dx.doi.org/10.1080/00423110802331559. 2009.

[5] Auciello, J., Ignesti, M., Malvezzi, M., Meli, E. \& Rindi, A., Development and validation of a wear model for the analysis of the wheel profile evolution in railway vehicles. Vehicle System Dynamics, 50(11), pp. 1707-1734, 2012. http://dx.doi.org/10.1080/00423114.2012.695021

[6] Bruner, M. \& Rizzetto, L., Dynamic simulation of tram-train vehicles on railway track. WIT Transactions on the Built Environment, vol. 101, pp. 491-501, 2008.

[7] Cortis, D., Bruner, M., Malavasi, G., Rossi, S., Catena, M. \& Testa, M., Estimation of the wheel-rail lateral contact force through the analysis of the rail web bending strains. Measurement, 99C, pp. 23-35, 2017, http://dx.doi.org/10.1080/00423114.2012.695021.

[8] Alessandria, M., Dotta, B. \& Licciardello, R.V., Long-term contact force measurements with the CML method. Ingegneria Ferroviaria, 66(11), pp. 929-948, 2011.

[9] Pearce, T. \& Sherratt, N., Prediction of wheel profile wear. Wear, 144, pp. 343-351, 1991. 